\title{
Lactate Stress Testing in 155 Patients with Mitochondriopathy
}

\author{
Josef Finsterer, Erika Milvay
}

\begin{abstract}
Objective: Few data are available about the diagnostic yield of the lactate stress test (LST) in a large group of patients with mitochondriopathy (MCP). Methods: Serum lactate was determined once before, three times during, and once after a 15-minute, constant $30 \mathrm{~W}$ workload on a bicycle in 62 controls, aged 17 to 84 years, 155 patients with MCP, aged 17 to 87 years, and 31 patients with neurological disorders other than MCP. Results: Lactate's upper reference limits at rest, 5, 10, 15 minutes after starting, and 15 minutes after finishing the exercise were 2.0, 2.1, 2.1, 2.1 and $1.8 \mathrm{mmol} / \mathrm{l}$ respectively. The test was regarded abnormal if more than two of the five lactate values exceeded the cut-off levels. Among the 103 patients with abnormal LST, 64 (62\%) had normal resting lactate. The sensitivity of the test was $67 \%$ and the specificity $94 \%$. Conclusion: The LST proved to have a high sensitivity and specificity in the detection of patients with MCP, being thus a simple but powerful tool to assess the impaired oxidative metabolism in MCP patients.
\end{abstract}

RÉSUMÉ: Test du lactate à l'effort chez 155 patients atteints de mitochondriopathie. Objectif: Il y a peu de données disponibles sur la valeur diagnostique du test du lactate à l'effort (TLE) chez un groupe important de patients atteints de mitochondriopathie (MCP). Méthodes: Le taux de lactate sérique a été déterminé avant, à trois reprises pendant et après un e activité physique de 15 minutes, d'intensité constante à $30 \mathrm{~W}$ sur une bicyclette, chez 62 contrôles âgés de 17 à 84 ans, 155 patients atteints de MCP, âgés de 17 à 87 ans et 31 patients présentant d'autres pathologies neurologiques. Résultats: Le point de coupe supérieur des valeurs de référence au repos, 5, 10, 15 minutes après le début de l'exercice et 15 minutes après la fin de l'exercice étaient de 2,0, 2,1, 2,1, 2,1 et 1,8 mmol/L respectivement. Le test était considéré comme normal si plus de deux des cinq valeurs de lactate étaient supérieures au point de coupe. Parmi les 103 patients dont le TLE était anormal, 64 (62\%) avaient un taux de lactate normal au repos. La sensibilité du test était de $67 \%$ et la spécificité de $94 \%$. Conclusion: Le TLE a démontré une sensibilité et une spécificité élevées pour la détection de patients porteurs d'une MCP. C'est un outil simple mais puissant pour évaluer l'altération du métabolisme oxydatif chez les patients atteints de MCP.

Can. J. Neurol. Sci. 2002; 29: 49-53

Serum lactate is frequently elevated at rest or during slight exercise in patients with mitochondriopathy (MCP). ${ }^{1-4}$ The increase of serum lactate mainly results from defective respiratory chain enzymes in the skeletal muscles, leading to a reactive change from aerobic to anaerobic phosphorylation of adenosine diphosphate and an equilibrium shift of the pyruvate/lactate reaction towards lactate. ${ }^{5-8}$ The increase of serum lactate during slight exercise is used for diagnostic purposes by means of the lactate stress test (LST). ${ }^{3,8-14}$ Despite increasing interest in this diagnostic tool and widespread application, little is known about the diagnostic yield of the LST in a large group of patients with MCP. This study was thus conducted, to assess the diagnostic yield of the LST in a large number of patients with MCP, diagnosed during five years.

\section{Patients AND Methods}

Included were all patients of the Neurological Hospital Rosenhügel, Vienna, in whom MCP was diagnosed between July
1995 and June 2000. Mitochondriopathy was diagnosed if two of the following four criteria were fulfilled: 1) clinical examination or instrumental findings indicative of a peripheral nervous system (PNS), central nervous system (CNS), ophthalmologic, otologic, cardiologic, endocrine, gastrointestinal or renal disorder alone or in combination, 2) muscle biopsy with typical features of a MCP, like $>5 \%$ ragged-red fibers, ${ }^{15}$ subsarcolemmal accumulation of mitochondria, reduced or negative staining for cytochrome-c oxidase with normal, increased or reduced nicotineamid dehydrogenase or succinate dehydrogenase reactivity, abnormally shaped and structured mitochondria on

\footnotetext{
From the Ludwig Boltzmann Institute for Research in Neuromuscular Disorders, Vienna, Austria, Europe

Received February 26, 2001. AcCePted in final Form August 7, 2001. Reprint requests to: J. Finsterer, postfach 348, 1180 Wien Austria, Europe
} 
electron microscopy, and intramitochondrial paracristalline inclusions, 3) confirmed oxidative enzyme defect on biochemical investigation of the muscle homogenate, and 4) proven or new pathogenic mitochondrial DNA (mtDNA) mutation on molecular genetic analysis. Muscle biopsy was carried out if the clinical examination was indicative of a MCP, if the EMG was neuropathic, myopathic or unspecifically abnormal (normal motor unit action potential duration, but abnormal spontaneous activity or increased percent polyphasia), or if the family history was positive for MCP. Patients with chronic alcoholism, malignancies, and those taking biguanids, valproate, corticosteroids, salicylate or oral contraceptives were excluded, since lactate may be increased under these conditions. Patients with diabetes, renal failure or hepatopathy were included only if these abnormalities were compensated at the time when the LST was carried out. All MCP patients who were physically capable, performed the LST. Patients with neurological disorders other than MCP and not fulfilling any of the exclusion criteria, served as disease controls. Subjects without any symptoms or signs of a neurological disorder, and not fulfilling any of the above mentioned criteria, served as healthy controls.

After a rest of 10 minutes immediately before the test, lactate was determined for the first time (R1). Afterwards, subjects were told to cycle continuously at $30 \mathrm{~W}$ on a paddle-rate independent electronic bicycle ergometer (E980, Tunturi, Piispanristi, Finland) for 15 minutes. During this exercise, lactate was determined 5, 10 and 15 minutes after starting cycling. Finally, lactate was determined 15 minutes after finishing cycling (R2). ${ }^{3,4,8}$ Lactate was measured by means of the commercially available Ektachrome Clinical Chemistry Slide (LAC, Kodak, Rochester-N.Y., USA). ${ }^{3,4,11}$ The LST was interpreted as abnormal if more than two of the five individual lactate values exceeded the corresponding cut-off values. This criterion for abnormality was chosen as it gave the highest sensitivity and specificity among various other criteria tested $(1,2,3,4$ or 5 values increased or 1, 2 or 3 values increased during exercise). All patients gave informed consent prior to their inclusion. The study was approved by the institutional review board for human experimentation.

\section{Results}

\section{Controls}

The LST was carried out in 62 healthy subjects, 31 women, 31 men, aged 17 to 84 years. Lactate levels at R1, S5, S10, S15 and R2 were not significantly different between the genders (all $\mathrm{P}>0.05$ ), were normally distributed, and were independent of age. Mean (SD) of the serum lactate at R1, S5, S10, S15 and R2 is given in the Table. The upper reference limits (mean+2SD) of serum lactate at R1, S5, S10, S15 and R2 were 2.0, 2.1, 2.1, 2.1 and $1.8 \mathrm{mmol} / \mathrm{l}$ respectively (Table and Figure).

\section{Disease controls}

In 31 patients with neurological disorders other than MCP, 16 women and 15 men, aged 21-77 years, the LST was carried out during the diagnostic work-up. Nine of these patients had polyneuropathy, three each limb girdle muscular dystrophy and myopathy of unknown etiology, two each myasthenia gravis, facio-scapulo-humeral muscular dystrophy, neuroborreliosis, and one each spinal muscular atrophy, polyarthritis, M. Refsum, amyotrophic lateral sclerosis, phosphofructokinase deficiency, multiple sclerosis, muscular dystrophy, oculo-pharyngeal muscular dystrophy, myoadenylate-deaminase deficiency and a carrier state for Duchenne muscular dystrophy. Individual values of the serum lactate values at R1, S5, S10, S15 and R2 are given in the Figure. Mean (SD) of the serum lactate at R1, S5, S10, S15 and R2 is given in the Table. Mean serum lactate was not significantly different from controls. Except for the patient with M. Refsum and oculopharyngeal muscular dystrophy, the LST was normal in the remainder.

Table: Mean (SD) values of serum lactate at rest before the exercise (R1), 5, 10 and 15 minutes after starting cycling (S5, S10, S15), and 15 minutes after finishing cycling (R2), in 62 healthy controls, 155 patients with MCP, and 31 patients with neurological disorders other than MCP. Additionally, P-values of the t-test are given.

\begin{tabular}{|c|c|c|c|c|c|}
\hline & $\begin{array}{l}\text { Healthy } \\
\text { Controls }\end{array}$ & $\begin{array}{l}\text { MCP } \\
\text { patients }\end{array}$ & P-value & $\begin{array}{l}\text { Non-MCP } \\
\text { patients }\end{array}$ & P-value \\
\hline Number (n) & 62 & 155 & nd & 31 & nd \\
\hline Sex ratio $(\mathrm{f} / \mathrm{m})$ & $31 / 31$ & $83 / 72$ & nd & $16 / 15$ & nd \\
\hline Age (years) & $42.6(15.3)$ & $54.3(16.0)$ & 0.098 & $50.3(15.2)$ & 0.147 \\
\hline $\mathrm{R} 1(\mathrm{mmol} / \mathrm{l})$ & $1.26(0.38)$ & $1.80(0.76)$ & 0.265 & $1.4(0.47)$ & 0.432 \\
\hline $\mathrm{S} 10(\mathrm{mmol} / \mathrm{l})$ & $1.41(0.36)$ & $3.04(1.54)$ & 0.001 & $1.6(0.6)$ & 0.359 \\
\hline $\mathrm{S} 15(\mathrm{mmol} / \mathrm{l})$ & $1.34(0.39)$ & $3.10(1.71)$ & 0.001 & $1.6(0.6)$ & 0.287 \\
\hline $\mathrm{R} 2(\mathrm{mmol} / \mathrm{l})$ & $1.16(0.30)$ & $2.35(1.46)$ & 0.001 & $1.3(0.4)$ & 0.611 \\
\hline
\end{tabular}

MCP: mitochondriopathy; Non-MCP: neurological disorders other than MCP; n: number of patients; f: female; m: male; nd: not done 


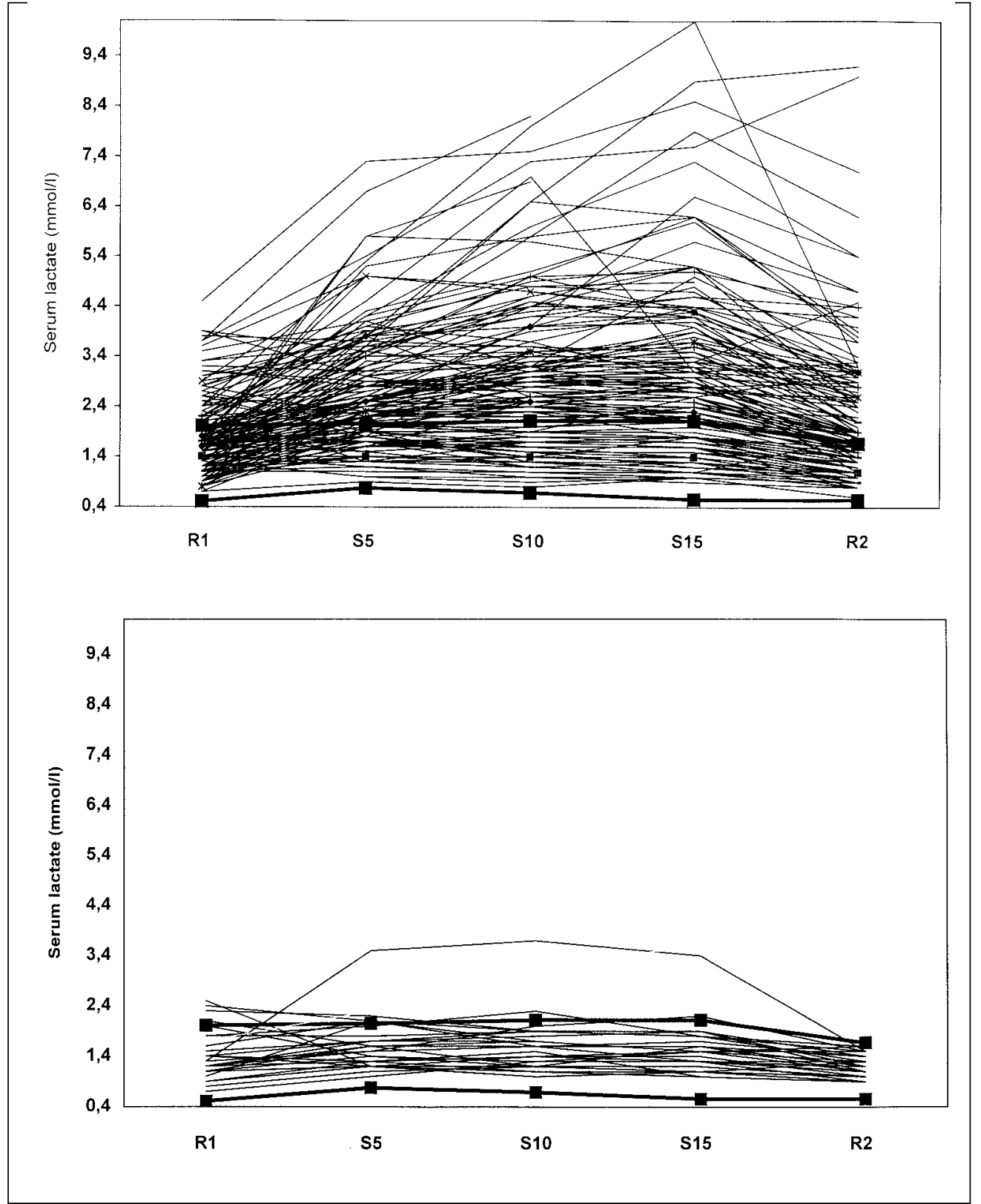

Figure: Individual LST results of, 155 patients with MCP (upper panel) and 31 patients with neurological disorders other than MCP (lower panel). Reference limits calculated from the results of 62 healthy controls are given as full squares

\section{MCP patients}

During the observational period, MCP was diagnosed in 179 patients. Of these, 155 patients, 83 women, 72 men, aged 17 to 87 years, were physically capable to perform the LST and did not fulfill any of the exclusion criteria. All of them had undergone muscle biopsy. Sixty-three patients showed ragged-red fibers $>5 \%(41 \%), 149$ patients had reduced or absent staining for cytochrome-c oxidase (96\%), and 110 patients had abnormally shaped or structured mitochondria $(71 \%)$. The EMG was myogenic in $68(43 \%)$, neurogenic in $25(16 \%)$, unspecifically abnormal in $18(11 \%)$, and normal in 44 patients (28\%). The most frequent manifestations of MCP were myopathy (97\% of 155 ), abnormal visually evoked potentials (63\% of 57), dilation of the cardiac cavities (49\% of 42), neuropathy ( $43 \%$ of 155 ), myocardial thickening (42\% of 42 ), focal or diffuse cerebral demyelination (34\% of 72), short stature (30\% of 63), impaired hearing (29\% of 155), and impulse generation or conduction defects $(27 \%$ of 42$)$. One hundred and fifty-three patients fulfilled diagnostic criterion 1, 151 patients criterion 2, 12 patients criterion 3 (biochemical investigations of the muscle homogenate were carried out in 24 of the 155 patients), and 35 patients criterion 4. Both patients who did not fulfill criterion 1, 
fulfilled criterion 2 and 4 . Four patients did not have myopathy, neither clinically nor on muscle biopsy, but they all fulfilled criteria 1 and 4.

In the majority of the cases, the LST was carried out during the diagnostic work-up. In a few patients the LST was carried out after the diagnosis had been established. Individual values of the serum lactate at R1, S5, S10, S15 and R2 are given in the Figure. Mean (SD) serum lactate levels at rest and during exercise are given in the Table. Resting lactate was normal in 114 patients (74 $\%)$ and increased in 41 (26\%). Among the patients with increased R1 value, three had a normal LST. In nine patients $(6 \%)$ the R2 value further increased compared to the highest value during exercise. The LST was abnormal in 103 patients $(67 \%)$. Among these, resting lactate was normal in 64 patients $(62 \%)$. In three patients without myopathy the LST was abnormal. In patients with abnormal LST, the EMG was myogenic in $47(46 \%)$, neurogenic in $16(16 \%)$, unspecifically abnormal in $13(13 \%)$, and normal in 27 patients (26\%). Fortysix patients with abnormal LST (45\%) showed ragged-red fibers $>5 \%, 98$ patients $(95 \%)$ reduction of cytochrome-c oxidase activity on muscle biopsy, and 80 patients (78\%) abnormally shaped and structured mitochondria.

\section{Discussion}

Despite great progress in the diagnostic procedures, particularly molecular genetic techniques, the LST has defended its role as a screening method in the diagnostic work-up of MCPs. This might be due to the fact that the LST is cheap, quick and easy to perform, even by unskilled technicians, and is applicable to the majority of the MCP patients. ${ }^{4,8}$ Unfortunately, there is still no consensus about the protocol the LST should follow in the daily routine. Among various protocols to perform the LST, the most frequently applied is the one proposed by Zierz et $\mathrm{al}^{8,11,16}$ which follows a similar procedure as in the present investigation but regards an individual result abnormal only if serum lactate exceeded $1.5 \mathrm{mmol} / \mathrm{l}$ at rest and $2.0 \mathrm{mmol} / \mathrm{l}$ during exercise. In several other studies subjects were stressed according to a protocol different from the one applied in the present investigation. ${ }^{6,10,12,13,16-20}$ Generally, a disadvantage of protocols which require an absolute workload is that differences in muscle mass and physical conditioning are not considered, although it is well-known that the lactate increase under a fixed workload may be due to deconditioning and reduced body mass. ${ }^{17,21}$ Although a workload relative to the maximal is assumed to give a higher sensitivity and specificity, particularly if the maximal workload is reached stepwise, results of a recent investigation show that cycling with $30 \%$ of the maximal workload does not increase the diagnostic yield of the LST. ${ }^{22}$ This unexpected finding might be due to the determination of the maximal workload by an "all work-out exercise". Another modification of the LST, which relies on the calculation of the difference between resting lactate and the maximal lactate value during exercise, does not increase the diagnostic yield of the LST either (unpublished data). In previous studies, on smaller groups of patients, the sensitivity of the test ranged between 66 and $100 \%,{ }^{3,8-14}$ being thus in line with our Figure. Why the sensitivity of the present investigation to detect MCP was not higher than previously reported, might be due to the selection bias, the test protocol, and the applied criteria for abnormality. ${ }^{3,4}$ The abnormal LST in a patient with Refsum's disease might be due to a special diet this patient had to follow. In the patient with oculopharyngeal muscular dystrophy the abnormal LST was attributed to the catabolic state this patient was in at the beginning of hospitalization.

Contrary to previous reports, ${ }^{11,13}$ serum lactate was normal at rest before the exercise in three-quarters of the included patients with MCP. This might be due to the test protocol, demanding a rest of 10 minutes before the test and the selection bias. That two-thirds of the MCP patients with abnormal LST had normal resting lactate, stresses the importance of measuring serum lactate not only at rest, but also during slight exercise when MCP is suspected. ${ }^{4,21}$ Additionally, the LST should be carried out in patients with normal electrophysiological findings but having clinical evidence of MCP. ${ }^{4}$ Particularly in patients who refuse muscle biopsy, the LST may be helpful to support the diagnosis. ${ }^{3,4,10}$ However, a normal LST does not exclude MCP. Increased resting lactate but normal LST in three of the investigated patients remains unexplained. Further increase of serum lactate at R2 in nine patients may be due to a prolonged wash-out of serum lactate.

Usually there is a good relation between the LST and the degree of muscle affection on histopathological findings. ${ }^{21}$ In some cases, however, an abnormal LST may not be associated with a reduction of the oxidative enzyme stainings. ${ }^{21}$ In such cases, the heteroplasmy rate in the skeletal muscle may be low. The close relation between the LST and the muscle pathology in the present investigation is supported by the fact that the organ most often affected was the skeletal muscle. In only four patients there was no evidence of myopathy. That the LST was abnormal in three of these patients favors the LST also as a screening test for subclinical myopathy in MCP. The low frequency of abnormal biochemical findings in the present investigation might be due to the low heteroplasmy rate and the fact that there was only a checkerboard reduction of oxidative enzymes in most cases. ${ }^{2,4}$ That not all patients with abnormal EMG, ragged-red fibers $>5 \%$, reduced oxidative enzyme staining, abnormal mitochondria or proven mtDNA mutation also had an abnormal LST, supports the view that the diagnosis of MCP requires a multiprofessional effort and the synopsis of clinical, serological, electrophysiological, histopathological, biochemical and genetic data. $^{2}$

In conclusion, this study showed that the LST was abnormal in two-thirds of the patients with MCP. The specificity of the test is high. The test supplements clinical, bioptical and genetic investigations. The test is easy to perform, cheap and reliable. The test is particularly helpful in patients with strong clinical evidence of a MCP, but who refuse muscle biopsy, or in whom genetic screening is not informative.

\section{REFERENCES}

1. DiMauro S, Bonilla E, Zeviani M, Nakagawa M, DeVivo DC. Mitochondrial myopathies. Ann Neurol 1985: 17: 521-538.

2. Morgan-Hughes JA. The mitochondrial myopathies. In: Engel AG, Franzini-Armstrong C, eds. Myology. Basic and Clinical. New York: McGraw-Hill, 1994: 1610-1651.

3. Finsterer J, Shorny S, Capek J, et al. Lactate-stress test in the diagnosis of mitochondrial myopathy. J Neurol Sci 1998: 159: 176-180. 
4. Finsterer J, Eichberger H, Jarius C. Lactate stress testing in 54 patients with mitochondriopathy. Eur Arch Psych Clin Neurosci 2000: 250: 36-39.

5. Hashef L, Lane RJ. Screening for mitochondrial cytopathies: the sub-anaerobic threshold exercise test (SATET). J Neurol Neurosurg Psychiatry 1989: 52: 1090-1094.

6. Land JM, Hockaday JM, Hughes JT, Ross BD. Childhood mitochondrial myopathy with ophthalmoplegia. J Neurol Sci 1981: 51: 371-382.

7. Shapira AHV, DiMauro S. Mitochondrial Disorders in Neurology. Oxford: Butterworth Heinemann, 1994: 75-76.

8. Zierz S, Meeßen S, Jerusalem F. Laktat- und Pyruvatspiegel in der Diagnostik mitochondrialer Myopathien. Nervenarzt 1989: 60: 545-548.

9. Haller RG, Bertocci LA. Exercise evaluation of metabolic myopathies. In: Engel AG, Franzini-Armstrong C, eds. Myology. Basic and Clinical. New York: McGraw-Hill, 1994: 807-821.

10. Chan A, Gold R, Arp S,et al. A standardised bicycle ergometer test in the diagnosis and monitoring of mitochondrial myopathies. Nervenarzt 1998: 69: 472-484.

11. Dengler R, Wohlfarth K, Zierz S, Jöbges M, Schubert M. Muscle fatigue, lactate, and pyruvate in mitochondrial myopathy with progressive external ophthalmoplegia. Muscle Nerve 1996: 19: 456-462.

12. Petty RKH, Harding AE, Morgan-Hughes JA. The clinical features of mitochondrial myopathy. Brain 1986: 109: 915-938.

13. Vissing J, Galbo H, Haller RG. Exercise fuel mobilisation in mitochondrial myopathy: a metabolic dilemma. Ann Neurol 1996: 40: 655-662.
14. Shapira Y, Cederbaum SD, Cancilla PA, Nielsen D, Lippe BM. Familial poliodystrophy, mitochondrial myopathy, and lactate acidaemia. Neurology 1975: 25: 614-621.

15. Collins S, Byrne E, Dennett X. Contrasting histochemical features of various mitochondrial syndromes. Acta Neurol Scand 1995; 91: 287-293.

16. Schmidt M, Kunkel M, Schuff-Werner P, et al. Standardised aerobic treadmill ergometry in healthy subjects and patients with mitochondrial and non-mitochondrial myopathies. Nervenarzt 1997; 68: 831-835.

17. Johnson MA, Turnbull DM, Dick DJ, Sherratt HSA. A partial deficiency of cytochrome $\mathrm{C}$ oxidase in chronic progressive external ophthalmoplegia. J Neurol Sci 1983; 60: 31-35.

18. Ogasahara S, Nishikawa Y, Yorifuji S, et al. Treatment of KearnsSayre syndrome with coenzyme Q10. Neurology 1986; 36: 4553.

19. Sengers RCA, ter Haar BGA, Trijbels JMF, et al. Congenital cataract and mitochondrial myopathy of skeletal and heart muscle associated with lactic acidosis after exercise. J Pediatrics 1975; 86: $873-880$

20. Siciliano G, Renna M, Nanca ML, et al. The relationship of plasma catecholamine and lactate during anaerobic threshold exercise in mitochondrial myopathies. Neuromusc Disord 1999; 9: 411-416.

21. Jackson MJ, Schaefer JA, Johnson MA, et al. Presentation and clinical investigation of mitochondrial respiratory chain disease. A study of 51 patients. Brain 1995; 118: 339-357.

22. Finsterer J, Milvay E. Diagnostic yield of the lactate stress test under absolute or relative workload in respiratory chain disorders. J Neurosci Meth 2001;108:65-70. 